\title{
A reforma da Carta da ONU
}

\author{
JOSÉ CARLOS DE MAGALHÃES
}

$\mathrm{P}$

ROPOSTAS E ESTUDOS para a reforma da Carta da ONU datam de mais de 20 anos e revelam contradições, aspirações, idealismos e oportunismos, que iniciativas similares sempre abrigam. Mais do que isso, tais estudos fazem aflorar debates sobre o caráter com que foi concebida e sua importância no mundo atual.

Uma primeira indagação que provoca refere-se a se a Carta constitui apenas um tratado multilateral intergovernamental ou se, ao contrário, trata-se de um instrumento constitucional que organiza a ordem internacional, ao estabelecer princípios e propósitos comuns a todas as nações a ela subordinadas, independentemente de a terem ou não subscrito.

A questão é relevante, pois, se mero Tratado, sua modificação se revestiria de mais simplicidade, ao passo que, se Constituição, o processo de alteração, emenda, ou interpretação deveria observar as limitações e rigores próprios de toda constituição. Em sua origem, esta foi a opinião da doutrina ocidental em geral (Franck, 1989), ao contrário da soviética, sempre preocupada com a posição minoritária dos países do bloco comunista na Organização (Morozov, 1969). A decisão proferida no caso Certas Despesas das Nações Unidas, pela Corte Internacional de Justiça inclinou-se pela última tendência, com a dissidência dos juízes dos países socialistas (McWinney, 1986).

Independentemente dessa decisão, que data de 20 de julho de 1962, os acontecimentos que a sucederam e a realidade atual deixam patente possuir a Carta da ONU caráter de instrumento constitucional, organizador da comunidade internacional, com princípios e propósitos de acatamento generalizado, inclusive pelos raros países que dela não fazem parte e pelos Estados novos, egressos do sistema colonial que a própria ONU extinguiu. Daí a importância atribuída às propostas de sua reformulação, havendo quem tema poder tal iniciativa abrir verdadeira caixa de Pandora, provocando modificações indesejadas que a afetem profundamente em sua estrutura ou a desnaturem.

O papel da ONU nas relações internacionais tem sido sempre destacado, pelas múltiplas facetas que possui e pelo que dela se espera. Desde sua criação, encontra-se em permanente evolução, em processo dinâmico que não experimentou longos momentos de estabilidade. Institucionalizada em tempo de guerra, para manter a paz internacional, vale-se de estratégia complexa, não concebida 
conscientemente, que lhe permite examinar e decidir sobre situações de tensão, derivadas de conflitos políticos, religiosos, raciais, econômicos, ou de outra natureza.

Nestes 50 anos de existência, a ONU cresceu de importância, sem deixar de sofrer de permanente crise. A influência ocidental, sob liderança dos Estados Unidos, jamais foi abalada no período da Guerra Fria, pela pressão da União Soviética e dos países que gravitavam em sua órbita. Certos eventos ilustram a preponderância americana, a começar pelo episódio da guerra da Coréia e pela paralisação do Conselho de Segurança, pela URSs, forçada a usar de seu poder de veto sucessivas vezes, para evitar a aprovação de resoluções contrárias a seus interesses políticos. A ocidentalização da ONU é fato conhecido e reconhecido.

Os Estados Unidos sempre a apoiaram e estimularam o uso de seu sistema, sobretudo a Corte Internacional de Justiça, reiteradamente prevista como competente para dirimir controvérsias nas cláusulas de jurisdição dos tratados de cooperação, amizade e comércio que negociaram com diversos países (Franck, 1989).

O predomínio ocidental nos principais órgãos da ONU, que Stalin qualificava como um lugar perigoso (Moynhan, apud Franck, 1989), nunca foi seriamente abalado pelas iniciativas da URSS, não obstante a divisão do mundo entre o sistema capitalista e o comunista, com o estabelecimento da bipolaridade que, por muito tempo, presidiu as relações internacionais. Com o derruir do sistema centralizador estatal e de economia planificada, e com a extinção da URSS, alterou-se profundamente o quadro internacional. Todavia, bem antes do debacle do comunismo, a liderança ocidental já havia sido posta em xeque pelos países não-alinhados, reunidos posteriormente no Grupo dos 77 , que somavam mais de 120 , passando a comandar grande parte das comissões e subcomissões formadas pelos diversos órgãos da Organização

De fato, se o poderio bélico e o suporte ideológico da antiga URSS não foram capazes de abalar o prestígio dos EUA na ONU, travando-se a batalha da Guerra Fria fora de seus quadros, os países do chamado Terceiro Mundo aproveitaram a vantagem numérica do grupo para influir, criando comissões, subcomissões e organismos subsidiários da Assembléia Geral, como a UNCTAD, conseguindo reduzir de importância o papel dos EUA.

Principais financiadores da Organização (1), aquele país não se conformou facilmente e a reação se fez notar em diversas manifestações. Dentre estas, destaca-se a retirada da Organização Internacional do Trabalho, sob o argumento de que havia sido transformada em palco político, deixando de lado seus objetivos fundamentais. A OIT estava dominada pelos países do Terceiro Mundo (2). Posteriormente, a saída da UNESCO foi justificada pela mesma razão e pelo descontrole administrativo em que se encontrava (3). A seguir, o surpreendente afastamento da Corte Internacional de Justiça do processo em que litigava com a 
Nicarágua, sob a alegação de que o pleito se revestia de natureza política, de competência do Conselho de Segurança e já levada ao conhecimento da Organização dos Estados Americanos. Ademais, a Nicarágua não teria ratificado sua submissão à Corte (4). O não acolhimento das preliminares de falta de competência, por expressiva maioria, com votos de representantes de países industrializados, fez com que os Estados Unidos deixassem o processo, retirando a concordância com a jurisdição obrigatória da Corte.

A desconfiança daquele país sobre a imparcialidade da Corte, que tantas vezes invocou e prestigiou, se revela, ainda, na carta que o Departamento de Estado enviou ao Secretário Geral da ONU, datada de 6 de abril de 1984, comunicando que a jurisdição compulsória da Corte Internacional de Justiça "não se aplica a controvérsias com qualquer Estado da América Central, provenientes de, ou relacionadas com eventos na América Central, os quais serão resolvidos da forma como as partes venham a acordar" (I L M, 1984:670)

A disposição de manter comportamento contrário ao desenvolvimento da Organização continuou, com a restrição imposta aos representantes e membros de delegações de alguns países comunistas de livre circulação pelo território norte-americano, tradicionalmente permitida, mesmo no auge da Guerra Fria (5). Valendo-se do Tratado de Sede, que prevê a autorização antecipada para viagens para fora da Cidade de Nova Iorque, aquele país adotou comportamento rígido, contrariando procedimento anterior.

Ainda dentro dessa tendência situa-se a decisão de impedir a entrada no país do líder da Organização de Libertação da Palestina, para participar de debates na Assembléia Geral (6), realizada em Genebra, ante a recusa americana (Reisman, 1989), bem como a tentativa de fechamento da Missão Permanente de Observação daquela organização junto à ONU, com base no Anti Terrorrist Act, de 1987. A negativa do visto de entrada provocou pedido da Assembléia Geral de Parecer Consultivo à Corte Internacional de Justiça, que decidiu que os Estados Unidos estavam obrigados a participar de um processo arbitral para resolver a questão, como previsto no Tratado de Sede (7). O Judiciário norte-americano, por sua parte, em decisão de juiz federal que honra o sistema jurídico daquele grande país, julgou que o Anti Terrorist Act não se aplicava às missões acreditadas junto à ONU (8). Curiosamente, o governo não apelou da sentença, por razões de conveniência política, dando por encerrada a questão.

A pouca consideração devotada à Organização foi, contudo, circunstancial, motivada pelo temporário desprestígio do país, em face do fortalecimento político dos países do Terceiro Mundo. Logo os EUA voltaram a dela se servir, para revigorar o adormecido Conselho de Segurança e conseguir a aprovação para a ação bélica na guerra do Golfo Pérsico, reproduzindo o sucesso da estratégia utilizada para a intervenção armada contra a Coréia do Norte, autorizada pelas 
Resoluções 82 e 83, de 25 e 27 de junho de 1950 (9), desta vez com o apoio da Rússia e da comunidade internacional em geral, ante a agressão injustificada e irracional do Iraque.

Não obstante, continuaram os EUA a atuar diplomaticamente para debelar conflitos regionais sem a intervenção da Organização, agindo isoladamente, com apoio de aliados, nas disputas do Oriente Médio. Os acordos de Camp David, pacificando Egito e Israel, bem como os que reuniu Israel e Jordânia e Israel e a OLP foram vitórias individuais da diplomacia norte-americana, feitas à margem da ONU, em importante área de conflitos.

As ações bélicas também foram decididas fora do âmbito da ONU, como ocorreu no episódio dos mísseis em Cuba e na intervenção do Panamá, tendo como paralelo as iniciativas unilaterais da URSS na Hungria, Checoslováquia e Afeganistão. A guerra do Vietnã, igualmente, foi conduzida à margem da ONU, sendo significativos a extensa literatura e o debate doutrinário produzidos sobre a constitucionalidade das decisões do governo norte-americano em seu envolvimento na guerra não-declarada, sem qualquer preocupação com a ausência de decisão do Conselho de Segurança que autorizasse a intervenção militar (10).

Essa marginalização, como sempre, mostrou-se temporária e, novamente, os EUA acionaram o Conselho de Segurança para conseguir apoio para intervir no Haiti, em controvérsia de características nitidamente internas, visto que se tratava de restabelecer no poder o presidente deposto e exilado. A ONU serviu aos propósitos políticos dos EUA que, com a autorização concedida, não poderia sofrer a imputação de agir arbitrariamente em interesse próprio (11). No mesmo quadro poder-se-ia incluir as resoluções do Conselho de Segurança que impuseram embargo à Líbia, Somália e Sérvia e Montenegro (antiga Iugoslávia), sem contar as que provocaram as operações militares na Bósnia, no Camboja e na Somália, estas ditadas por motivos humanitários. No entanto, a invasão de Granada e a abdução de Noriega, do Panamá, foram realizadas sem o apoio e sem o conhecimento da Organização.

Essa breve resenha está a demonstrar que a ONU, em seus altos e baixos, depende muito das grandes potências para sobreviver e qualquer reforma na Carta que a instituiu deve ter presente aquela realidade, sob pena de se fazer repetir o destino da Liga das Nações.

\section{Ampliação do poder de veto}

O poder de veto nas votações do Conselho de Segurança conferido aos países vencedores da Segunda Guerra Mundial e à China, como forma eficaz de manter na Organização as grandes potências de então, reproduzindo de certa forma o Concerto Europeu resultante do Congresso de Viena de 1815, é um 
dos pontos que tem merecido atenção. A realidade de 1945 é bem diversa da que o fim do século assiste, na qual países como França, Inglaterra e China não possuem expressão maior, pois mesmo reconhecendo a liderança dos EUA ou da URSS, sempre se limitaram a acompanhar o veto dos líderes, tendo a China dele se utilizado apenas uma vez e a França em duas oportunidades, revelando consciência da falta de poder e do papel de coadjuvantes que sempre desempenharam (Franck, 1988).

Paralelamente, países como Brasil, Alemanha, Japão e Índia ascenderam a uma posição de importância econômica e social que recomendaria sua inclusão entre os membros permanentes. A ampliação se justificaria, até, pela multipolarização do sistema político internacional, não mais dividido em duas ideologias conflitantes, ou em dois sistemas antagônicos de ordem pública, mas em diversos centros culturais e econômicos, dentre os quais têm expressão os países emergentes que traduzem aspirações comuns de comunidades nacionais não industrializadas ou em vias de desenvolvimento, ao lado das que já se afirmaram como potências econômicas influentes, como a Alemanha e o Japão com responsabilidades compatíveis com a nova situação que desfrutam, soterrado o estigma de países vencidos na Segunda Grande Guerra e considerados inimigos na acepção dos arts. 53 e 107 da Carta.

Essa reorganização do Conselho de Segurança é indispensável, ante a importância de suas atribuições, dentre as quais se destaca a de definir uma situação de ameaça à paz, que justifica a intervenção da organização e o emprego da força. Diversas manifestações revelam a amplitude que pode ser dada ao conceito, dependendo sempre da perspectiva de quem o formula. O subdesenvolvimento, a emigração maciça de refugiados, a devastação ambiental, a violação reiterada dos direitos humanos e o terrorismo têm sido invocados como formas de risco à paz internacional (Gaja, 1993).

De fato, a dinâmica das relações internacionais impõe que, em cada momento, sejam identificados atos que possam colocar em perigo a segurança coletiva. Cabendo ao Conselho de Segurança essa definição, e diante do caráter multicultural do mundo, é indispensável que aquele órgão reflita não mais apenas a realidade do momento em que foi concebido, mas a atual, na qual a ordem internacional se apresenta profundamente alterada, com a atuação no cenário internacional de novos atores como a multiplicidade de organizações regionais, a União Européia, os Estados novos, oriundos do processo de descolonizarão que a própria ONU empreendeu, as organizações não-governamentais, os grupos de pressão política e militar, as empresas privadas multinacionais, ou transacionais, com poder econômico e político próprios e desvinculados dos Estados de onde provém.

Todos esses atores e fatores estão a recomendar a reformulação daquele órgão, sobretudo no que toca ao poder de veto, usado algumas vezes em causa própria, como fez a Inglaterra no episódio da guerra das Malvinas (12), não mais 
compatível com a realidade atual. O Comitê Especial da Carta das Nações Unidas e de Fortalecimento do Papel da Organização, instituído pela Resolução 3349 (XXIX), de 15 de dezembro de 1975, após sucessivas reuniões, apresentou proposta, cuja aceitação, como é óbvio, dependerá da aquiescência dos membros permanentes do Conselho Essa proposta prevê, em resumo: o aumento do número de seus membros, com observância do princípio da repartição geográfica eqüitativa; a outorga do direito de veto a um ou dois membros não-permanentes, em rodízio, entre as diferentes regiões geográficas nele representadas; a limitação do exercício do direito de veto, com modificação do regulamento do Conselho sobre as questões procedimentais, evitando-se, com isso, a prática do duplo veto atualmente existente - impedimento a que se considere uma questão como de procedimento, sobre a qual não há o veto, e a aprovação da matéria pelo veto; e o convite aos membros permanentes para não dele não se valerem em questões relativas à paz internacional, além de outras, tendentes a evitar o abuso do exercício do direito de veto (13).

Essa proposta encontra obstáculo nos atuais membros permanentes, ciosos de suas prerrogativas exclusivas, cuja limitação somente poderia ocorrer por renúncia voluntária - o que é improvável - ou pela adoção de mecanismos alternativos que produzissem o mesmo efeito da deliberação Unidos para a Paz, tomada pela Assembléia Geral, para superar a paralisia do Conselho de Segurança, então incapacitado de resolver a crise gerada pela guerra da Coréia. Essa resolucão (14), tomada em 3 de novembro de 1950, por 52 votos, com duas abstenções e cinco contrários, dispõe que se o Conselho de Segurança não for capaz de resolver matéria de sua competência principal, a manutenção da paz, a Assembléia Geral, convocada por sete membros do Conselho de Segurança ou pela maioria de membros da ONU, pode se reunir e decidir em 24 horas em sessão de emergência. Trata-se de precedente que teve o apoio decidido dos EUA e dos países ocidentais de sua esfera de influência, dentre os quais França e Inglaterra. Durante a crise do canal de Suez, de que seis anos depois foram protagonistas diretos, esses dois países rebelaram-se contra tal resolução, em raro momento de rebeldia contra a liderança dos EUA, acoimando-a então de ilegal, fazendo coro tardio com a manifestação irada dos representantes e juristas da URSS (McWhinney, 1986:115).

Em 1992, Mikhail Gorbachev, em pronunciamento no Westminster College, revestido da autoridade de antigo presidente da URSS, também sugeriu a ampliação do Conselho, para incluir países como Índia, Japão, Polônia, México, Alemanha, Brasil, Canadá, Indonésia e Egito. Não obstante esse pronunciamento tenha sido feito quando não mais se revestia da autoridade de presidente da URSS, demonstra a profunda alteração no pensamento oficial que predominava naquele país, defensor do direito de veto, como estabelecido na Carta e infenso às alterações já cogitadas (15). Já o presidente Clinton, ao tomar posse, dispôs-se a aceitar apenas a Alemanha e o Japão na qualidade de membros permanentes, numa clara demonstração de que as propostas que incluem no Conselho países de 
menor expressão econômica, embora representativos de certas áreas geográficas e de densidade demográfica razoável, deverão encontrar grande dificuldade (Caron, 1993).

A reformulação do Conselho de Segurança tem relevância ainda pela feição nova que assumiu a comunidade internacional, com o desaparecimento da bipolaridade que a dividia e o maniqueísmo que a informava. O recente reativamento de suas atividades, fruto do interesse dos Estados Unidos em dele novamente se valer, fez ressurgir temas de importância, ainda mal resolvidos. É o caso do exercício do direito de veto em decisões sobre a cessação de penalidades aprovadas contra Estados infratores da paz mundial, como ocorreu com o Iraque, no episódio da guerra do Golfo. Pretende-se que, aprovada uma ação punitiva pelo Conselho de Segurança, somente outra resolução possa autorizar a sua extinção, não sendo lícito aos Estados deixarem de observar as normas punitivas, sem ferir a Carta. No passado, Estados Unidos e Inglaterra advogavam posição contrária à adotada nesse episódio, no qual lhes interessa manter as sanções, até decisão em contrário do Conselho, em que podem usar o direito de veto. A suspensão das sanções contra a Rodésia, aprovadas pelo Conselho de Segurança, foi decidida unilateralmente por EUA e Inglaterra, que consideravam haverem sido cumpridas as determinações impostas. Sendo silente a Carta sobre a suspensão das medidas coercitivas, cada Estado estaria autorizado a fazê-lo, sem ouvir o Conselho, contra o que se manifestou o representante da URSS. As sanções acabaram por ser levantadas por decisão logo após tomada, deixando, contudo, registrado o precedente do comportamento (Caron, 1993).

Outra iniciativa recente, a recomendar maior representatividade naquele órgão, é a instituição de Tribunal, em 25 de maio de 1993, conforme Resolução 827 , tomada por unanimidade (16), com o propósito de processar os responsáveis pela violação do direito humanitário, desde janeiro dede 1991, na antiga Iugoslávia, depois de se haver configurado o insucesso das tentativas feitas por Comissão de Direitos Humanos das Nações Unidas; Conferência sobre Segurança e Cooperação na Europa; Comunidade Européia; e por Conferência Internacional sobre a antiga Iugoslávia, bem como iniciativas aprovadas pelo próprio Conselho, que incluíam a condenação das atrocidades, sua publicação, divulgação e, finalmente, uma investigação (17). Ao Tribunal foi conferida competência para apreciar imputações de crimes de guerra e contra a humanidade, inclusive o genocídio, não abrangendo os crimes contra a paz, ao contrário do que se previra nos Tribunais de Nuremberg e de Tóquio. Esta, a propósito, é a primeira iniciativa da ONU, quanto à instituição de uma Corte Judiciária especial, para examinar e julgar delitos de guerra, depois daqueles tribunais polêmicos e ainda hoje contestados, sendo previsível que se institucionalize como meio eficaz de julgar delitos daquela natureza cometidos no âmbito interno dos Estados (18). Número significativo de países apresentaram sugestões e comentários, inclusive o Brasil, demonstrando o interesse da comunidade internacional pela iniciativa. 
Mas não é apenas a isso que se resume a pretendida reforma da Carta. Há críticas contundentes contra o papel desempenhado pelo Secretário Geral e a atuação da Assembléia Geral, responsável pela desordem instaurada pela multiplicidade de comissões, subcomissões e órgãos que criou, muito dos quais em duplicidade, gerando uma balbúrdia institucional causadora de grande confusão.

A grande crítica, no entanto, focaliza o sistema de votação, em que cada membro possui um voto, qualquer que seja sua população e presença no cenário internacional. Miniestados, como Seychelles, Antígua e Barbuda, Granada e República Dominicana, com população de alguns milhares de habitantes, tem o mesmo voto que Índia e China, para referir apenas ao aspecto demográfica (Senarclens, 1988). Em 1984, 29 Estados possuíam menos de um milhão de habitantes, número expressivo capaz de influir no resultado de qualquer votação de relevância e, por isso mesmo, de dar margem à considerações de falta de realismo e de legitimidade em resoluções que não contam com o apoio dos países de maior expressão, senão das grandes potências.

No entanto, a Assembléia Geral é o órgão mais importante da Organização e desempenha papel relevante em sua evolução e no desenvolvimento do direito internacional, pois reflete aspirações gerais da comunidade como um todo. Os temas que selecionou para conferências especiais denotam preocupações específicas e estratégia eficaz para provocar o exame aprofundado de questões de interesse geral.

Nesse quadro, inclui-se a Conferência de Estocolmo sobre o meio ambiente, de 1972; a de Roma, sobre alimentação, em 1974; a de Bucareste, em 1974, também sobre alimentação; a do México, em 1975, sobre a mulher; a de Vancouver, em 1976, sobre agrupamentos humanos e, posteriormente, sobre emprego; a de Mar del Plata, sobre água (Senarclens, 1988:149) e tantas outras, como a do Rio, de 1990, sobre meio ambiente, de grande repercussão.

Tais encontros e as resoluções que produziram provocam estudos e chamam a atenção das autoridades estatais e dos diversos atores que influem na tomada de decisões, estabelecendo parâmetros e normas de conduta que acabam se impondo por sua própria autoridade, como é o caso das resoluções sobre meio ambiente, tortura e terrorismo, temas que têm preocupado a comunidade internacional como um todo, ao lado das questões relacionadas com o desenvolvimento econômico e a fome.

Dominada pelos países não alinhados de outrora, a Assembléia Geral tornou-se o palco para a exteriorização de aspirações, embora pouco servindo para a condução de atividades diplomáticas, ainda exercidas diretamente fora do âmbito da organização. A grande crítica que se lhe faz reside na forma tumultuária com que tem atuado, produzindo grande número de documentos, relatórios e informes, freqüentemente mal redigidos ou escritos de forma empolada, sem 
objetividade; outras vezes, versando sobre matérias já examinadas por outros órgãos ou comissões. Como quer que seja, a Assembléia Geral representa a comunidade internacional como um todo, em sua variedade de composição e multiplicidade de civilizações e culturas, não se justificando a pretensão de amoldá-la aos parâmetros dos países de tradição do direito comum, ou do direito codificado, oriundos da civilização greco-romana, que representa apenas parcela da comunidade internacional, embora dominante.

Além da Assembléia Geral, pretende-se disciplinar a atuação do Conselho Econômico e Social que tem atribuições idênticas à Comissão de Direitos Humanos e de vários comitês, em duplicidade que somente compromete a eficiência da Organização. A universalização da participação nesse Conselho, conferindo-lhe jurisdição exclusiva sobre certas matérias, como as relativas aos direitos humanos e atividades sociais das Nações Unidas, permitiria eliminar a atual duplicidade, em benefício de maior concentração de decisões e, ao mesmo tempo, atribuir à Assembléia Geral a tarefa de se ocupar exclusivamente de assuntos políticos.

Notas

l A contribuição dos EUA para o orçamento da ONU, que correspondia a 25\% do total das receitas da organização foi drasticamente reduzida em 1986, agravando-lhe a situação financeira. Cf. Pierre de Senarclens, La crise des Nations Unies, Paris, PUF, 1988, p. 141; art. 151 do Foreign Relations Authorization Act. Ver crítica de Thomas M. Franck, Unnecessary UN-bashing should stop. American Journal of International Law (doravante A.J.I.L.), v. 80, p. 337, 1986.

2 Em 6 de novembro de 1975, o Secretário de Estado, Henry Kissinger, reclamou ao Diretor Geral da OIT sobre a incursão da Organização em temas políticos e econômicos fora de sua competência. Em novembro do mesmo ano, foi admitida a OLP, como observadora. Os EUA se retiraram em 1977, somente retornando em 1980.

3 A saída dos EUA ocorreu em 1984, a ela seguindo-se a da Inglaterra e de Cingapura, acarretando redução de $30 \%$ no orçamento da entidade. Cf. Pierre de Senarclens, $L a$ crise des Nations Unies, Paris, PUF, 1988, p. 171.

4 O Departamento de Estado, em declaração de 18 de janeiro de 1985, sustentou que a controvérsia se revestia de caráter nitidamente político, não-apropriado para uma decisão judicial. Cf. International legal materials, v. 24, p. 246, 1985.

5 Host Country Travel Regulation dated 29 August 1985 addressed to the Secretary General by Acting Permanente Representative of the United States of America. Texto em A.J.I.L. v. 80 , p. $438-439$.

6 Segundo Declaração do Secretario de Estado, “a Organização de Libertação da Palestina, por meio de seus participantes, empregou terrorismo contra americanos; o Sr. Arafat, presidente da Organização dá suporte àqueles atos; o terrorismo e as pessoas 
com ele envolvidas representam séria ameaça aos cidadãos americanos e o Acordo de Sede com a ONU, contida na Lei Pública 80.357, reserva o direito de impedir a entrada dos que representem ameaça à segurança americana." United States Department of State: Statement on the Visa Applications of Yasser Arafat, A.J.I.L., v. 83, n. 1, p. 253 , jan. 1989.

7 Resolucão 229 B da Assembléia Geral e ICJ Advisory Opinion, abr. 1988.

8 Decisão proferida em ação promovida pelo governo dos EUA contra a Organização de Libertação da Palestina e mais quatro pessoas, tendo por objeto o fechamento da Missão Permanente de Observação junto à ONU. Cf. A.J.I.L., v. 84, n. 4, p. 833-837, 1988.

9 O emprego de forças americanas na Guerra da Coréia continua a despertar polêmica, como se vê do artigo de Louis Fischer, The Korean war: on what legal basis did Truman act?, A.J.I.L., v. 89 , n. 1, p. 21,1995 . O autor refuta o precedente como válido para autorizar os presidentes Bush e Clinton a enviarem tropas para o exterior, sem aprovação do Congresso americano.

10 Sobre $\mathrm{o}$ assunto vide, The Vietnam war and International Law, organizado por Richard Falk, Princeton University Press, 1968 e, em particular, William T. Burke, The legal regulation of minor international coercion: a framework of inquiry, p. 78-101.

11 Ilustrativa, a esse propósito, a observação de Ernest W. Levfever: "The United Nations on ocasion may be useful instrument to serve the paralel interests of the United States and other majors powers in addressing specific crises", Reining in the UN: mistaken the instrument for the actor, Foreign Affairs, v. 72, n. 3, p. 17-20, 1993. Observação similar faz Pierre de Senarclens, op. cit., p. 141.

12 Cfe. arts. 108 e 109 da Carta.

13 Nações Unidas, Assembléia Geral, Documents officiels: Rapport du Comité Spécial de la Charte des Nations Unies et du raffermissement du rôle de l'Organisation, 33 a. sessão suplemento n.33 (A-36/33), p. 42; Edward McWhinney, Les Nations Unies et la formation du droit, Pedone/Unesco, 1986, p 109-119; Bengt Brons, The present stage in the work of the Special Committee on the Charte of the United Nations and on the strengthening of the role of the Organization, in International Law at a time of perplexity - Essays in honour of Shabtai Rosenne, Martinus Nijhoff Publishers, 1989, pag. 73 e ss.

14 Res. 377 A (V) da A.G.

15 Vide, a propósito, G. I. Morozov, para quem a idéia de rever a Carta da ONU "de facto, tem raízes em escritos ocidentais sobre o direito internacional” . International Law and the UN, International law and the U.N. In: Contemporary Law, p. 127.

16 Texto integral em I.L.M., v. xxxII, n. 4, p. 1203-1205, julho 1992.

17 Resoluções 764, de 13 de julho de 1962; 771, de 12 de agosto de 1992; 780, de 6 de outubro de 1991.

18 Vide Relatório do Secretário Geral sobre a Resolucão 808 (1993), que aprovou a instalação do Tribunal, I.L.M., v. XxxII, n. 4, p. 1159, jul. 1993; sobre o assunto, vide também James C. O'Brien, The International Tribunal for Violations of International Humanitarian Law in the Former Yugoslavia, A.J.I.L, v. 87, p. 639-659, 1993. 
Referências bibliográficas

CARON, David D. The legitimacy on the collective authority of the Security Council. A.J.I.L., v. 87 , p. $552-588,1993$.

FRANCK, Thomas M. Legitimacy in the international system, A.J.I.L., v. 82, n. 4, p. 705-759, 1988.

Soviet initiatives: U.S. responses: new opportunities for reviving the United Nations system. A.J.I.L., v. 83, n. 3, p. 531 e ss., 1989.

GAJA, Giorgio. Reflexions sur le role du Conseil de Securité dans le nouvel ordre mondial. Revue Générale de Droit International Public, t. 97, p. 301, 1993.

I.L.M., v. XXIII, n. 3, maio de 1984, p. 670.

McWHINNEY, Edward. Les Nations Unies et la formation du droit. Pedone/unesco, 1986, p. 105-108.

MOROZOV, G.I. International Law and the U.N. In: Gregory Tunkim (org.), Contemporary International Law, Moscou, Progress Publishers, 1969, p. 118-140.

MOYNHAN, D.P. A dangerous place, 1978, apud Thomas M. Franck, op. cit., p. 534.

REISMAN, W. Michael. The Arafat visa affair: exceeding the bounds of host State discretion, A.J.I.L., v. 83, n .3, p. 519 e ss., 1989.

José Carlos de Magalhães é professor de Direito Internacional da Faculdade de Direito da USP.

Palestra feita pelo autor no Colóquio A Carta de São Francisco: 50 anos depois, organizado pela Área de Assuntos Internacionais do Instituto de Estudos Avançados na Sala do Conselho Universitário da usp no dia 26 de junho de 1995. 